\title{
A comparative study of gel polymer electrolytes based on PVDF-HFP and liquid electrolytes, containing imidazolinium ionic liquids of different carbon chain lengths in DSSCs 2 th
}

\author{
Vembu Suryanarayanan ${ }^{\mathrm{a}}$, Kun-Mu Lee ${ }^{\mathrm{b}}$, Wen-Hsien $\mathrm{Ho}^{\mathrm{c}}$, Hung-Chang Chen ${ }^{\mathrm{c}}$, \\ Kuo-Chuan $\mathrm{Ho}^{\mathrm{a}, \mathrm{b}, *}$ \\ ${ }^{a}$ Department of Chemical Engineering, National Taiwan University, Taipei 10617, Taiwan \\ ${ }^{\mathrm{b}}$ Institute of Polymer Science and Engineering, National Taiwan University, Taipei 10617, Taiwan \\ ${ }^{\mathrm{c}}$ Department of Product Development, Taiwan Textile Research Institute, Tucheng 23674, Taiwan
}

Available online 9 May 2007

\begin{abstract}
The photoelectrochemical characteristics of titanium dioxide $\left(\mathrm{TiO}_{2}\right)$-based dye-sensitized solar cells (DSSCs) containing gel polymer electrolyte (GPE) and organic liquid electrolyte (OLE) were studied in detail. GPE was prepared by adding poly(vinyidene fluoride-cohexafluoro propylene) (PVDF-HFP) to imidazolinium ionic liquids (IILs) of the type, 1-methyl-3-alkyl imidazolinium iodides (alkyl is $\mathrm{C}_{n} \mathrm{H}_{2 n+1}$, where $\left.n=3-10\right)$ in methoxy propionitrile (MPN) and the OLE contained the above molten salt in MPN. The IILs were synthesized in the laboratory and characterized by ${ }^{1} \mathrm{H}$ nuclear magnetic resonance spectroscopy (NMR). The conductivities $(\sigma)$ of both GPE and OLE decrease with increase in chain length $(n)$ of the alkyl group of IILs; however, the effect is more drastic in the former case. The performance of the DSSCs containing OLE increases with the increase in alkyl chain length of IIL from C3 to C7, whereas, there is a linear decrease in the efficiency of the DSSCs incorporated with GPE containing IIL of alkyl chain length from C3 to C10. The change in short circuit current density $\left(J_{\mathrm{SC}}\right)$ determines the cell efficiency as the $V_{\mathrm{OC}}$ of the DSSCs remains almost the same with increase of alkyl chain length of IILs for both the electrolytes. The change in $J_{\mathrm{SC}}$ values and the consistency of the $V_{\mathrm{OC}}$ of the DSSCs for both the electrolytes may be explained on the basis of increase in viscosity of IILs from C3 to C10 and the dominating role of the 4-tertiary butyl pyridine (TBP), respectively, on the phenomenon of charge recombination.
\end{abstract}

(C) 2007 Elsevier B.V. All rights reserved.

Keywords: Dye-sensitized solar cells; Gel polymer electrolyte; Imidazolinium iodides; Ionic liquid; PVDF-HFP

\section{Introduction}

Because of the possible low production cost and the expected high-energy conversion efficiency, dye-sensitized solar cells (DSSCs) with nanocrystalline $\mathrm{TiO}_{2}$, organic dyes and an electrolyte become a large-scale prevalent material for light harvesting [1]. These solar cells usually employ

\footnotetext{
This paper S4-P36 presented at the International Materials Research Congress (IMRC), Symposium 4-Photovoltaics, Solar Energy Materials and Thin Films, August 20-24, 2006, Cancun, Mexico.

*Corresponding author. Department of Chemical Engineering, National Taiwan University, Taipei 10617, Taiwan. Tel.: + 886223660739 ; fax: +886223623040 .

E-mail address: kcho@ntu.edu.tw (K.-C. Ho).
}

liquid electrolytes containing $\mathrm{I}^{-} / \mathrm{I}_{3}^{-}$redox couple as supporting electrolyte in order to reduce the dye cation, generated by the injection of the photo-excited electron. However, as far as long-term stability of the solar cell is considered, use of the liquid electrolytes must be avoided as the organic solvents evaporate slowly leading to decrease in cell performance. Hence, in order to improve the long-term stability of the solar cell, gel polymer electrolytes (GPEs) such as poly(acrolynitrile) [2-4], poly(ethylene glycol) [5], poly(oligoethylene glycol methacrylate) [6], poly(siloxaneco-ethylene oxide) [7], poly(butylacrylate) [8] and poly(vinyidene fluoride-co-hexafluoro propylene) (PVDF-HFP) $[9,10]$ with different plasticizers have been employed. Among them, PVDF-HFP shows relatively high ionic 
conductivities at room temperature and they are stable in the presence of $\mathrm{TiO}_{2}$ and $\mathrm{Pt}$ nanoparticles.

Imidazolinium iodides have been used as liquid [11-13] and quasi-solid-state electrolytes $[11,12,14-16]$ in the solar cells. They contribute to enhancement of conductivity of $\mathrm{I}^{-} / \mathrm{I}_{3}^{-}$electrolyte and their multilayer adsorption on the $\mathrm{TiO}_{2}$ surface leads to the enhancement in electron diffusion coefficient [17]. In this study, the photovoltaic performance of the DSSCs fabricated with GPE and organic liquid electrolyte (OLE), both incorporated with imidazolinium ionic liquids (IILs) of the type 1-methyl-3-alkyl imidazolinium iodides (alkyl is $\mathrm{C}_{n} \mathrm{H}_{2 n+1}$, where $n=3-10$ ) in methoxy propionitrile (MPN), have been compared under identical experimental conditions. This study brings a direct comparison on the performance of DSSCs containing different chain length of IILs in both liquid and gel systems and this is different from other Refs. $[9,10]$.

\section{Experimental section}

\subsection{Materials}

Anhydrous LiI, I 2 , poly(ethylene glycol) (PEG), 4tertiary butyl pyridine (TBP) and MPN were obtained from Merck. Tetrabutylammonium iodide (TBAI, + 98\%) and titanium (IV) isopropoxide $(+98 \%)$ were purchased from Acros and used as received. The N3 dye was the commercial product obtained from Solaronix S.A., Aubonne, Switzerland.

1-Alkyl-3-methylimidazolium iodide (Scheme 1) [18] were prepared by the quaternization reaction of 1methylimidazole (Fluka) with an equimolar amount of the corresponding alkyl iodide (RI) (Fluka) at $120^{\circ} \mathrm{C}$ for $12 \mathrm{~h}$ in cyclohexane, where $\mathrm{R}=\mathrm{C}_{n} \mathrm{H}_{2 n+1}(n=3-10)$. The products were washed with diethyl ether to remove remains of the starting materials and dried under vacuum at $75^{\circ} \mathrm{C}$ for $4 \mathrm{~h}$, and the purity was confirmed by $400 \mathrm{M} \mathrm{Hz}{ }^{1} \mathrm{H} \mathrm{FT}$ nuclear magnetic resonance spectroscopy (NMR) instrument (Bruker Avance) in $\mathrm{CDCl}_{3}$.

\subsection{Preparation of $\mathrm{TiO}_{2}$ thin films and the cell assembly}

The preparation of $\mathrm{TiO}_{2}$ precursor and the electrode fabrication were carried out based on the previous literature [19] except after autoclave treatment, where the solution was concentrated to $13 \mathrm{wt} \%$ and two types of pastes, namely, P1 and P2 were prepared by the addition of $30 \mathrm{wt} \%$ (with respect to $\mathrm{TiO}_{2}$ ) of poly (ethylene glycol) (PEG) having molecular weights of 20,000 and 200,000, respectively, to the above solution in order to control the pore diameters and to prevent the film from cracking during drying [20]. P2 was coated over P1 on a fluorinedoped tin-oxide (FTO) glass $\left(R_{\mathrm{sh}}=25 \Omega / \square\right.$, Sinonar Corp., Hsinchu, Taiwan), using glass rod. This bilayer $\mathrm{TiO}_{2}$ film is an efficient light-harvesting material, as confirmed from the previous study carried out in this laboratory [20].

An active area of $0.25 \mathrm{~cm}^{2}$ was selected from sintered electrode and the electrodes were immersed in $3 \times 10^{-4} \mathrm{M}$ solution of cis-di(thiocyanato)bis(2,2'-bipyridyl-4,4'-dicarboxylate)ruthenium (II) (N3) containing acetonitrile and tertiary butanol (in the volume ratio of $1: 1$ ) for $24 \mathrm{~h}$. The OLE and GPE contain an optimized electrolyte composition of $0.6 \mathrm{M}$ of IILs/0.2 M LiI/ $/ 0.08 \mathrm{M}^{\circ} \mathrm{I}_{2} / 0.5 \mathrm{M}$ of TBP and $5 \mathrm{wt} \%$ PVDF-HFP $/ 0.8 \mathrm{M}$ of IILs/0.12 $\mathrm{M}$ of $\mathrm{I}_{2} / 0.2 \mathrm{M}$ of TBP in MPN, respectively. The specified composition of the electrolyte was sprayed on both the dye-immobilized photoanode and Pt-sputtered (thickness of Pt is $100 \mathrm{~nm}$ ) FTO glass and they are physically sandwiched together using cell holders.

\subsection{Instrumentation}

The photoelectrochemical characterizations of the DSSCs were carried out by using an AM 1.5 simulated light radiation. The light source was a $450 \mathrm{~W}$ Xe lamp (Oriel, \#6266) equipped with a water-based IR filter and AM 1.5 filter (Oriel, \#81075). Conductivity measurement of solution was performed by electrochemical impedance spectroscopy (EIS) with two Pt electrodes conductance cell where the area of each $\mathrm{Pt}$ electrode is $1 \mathrm{~cm}^{2}$ and the distance between the two electrodes is $1 \mathrm{~cm}$. The cell constant is $0.55 \mathrm{~cm}^{-1}$, as calibrated from the standard aqueous $\mathrm{KCl}$ solution. Photoelectrochemical characteristics of the DSSCs were recorded with a potentiostat/ galvanostat (PGSTAT 30, Autolab, Eco-Chemie, the Netherlands) under constant light illumination of $100 \mathrm{~mW} / \mathrm{cm}^{2}$.

The photovoltage transients of assembled devices were recorded with a digital oscilloscope (LeCroy, model LT322). Pulsed laser excitation was applied by a frequency-doubled Q-switched Nd:YAG laser (Spectra-Physics laser, model Quanta-Ray GCR-3-10) with $2 \mathrm{~Hz}$ repetition rate at $532 \mathrm{~nm}$ and $7 \mathrm{~ns}$ pulse width at half height. The beam size was larger than $0.25 \mathrm{~cm}^{2}$ to cover the area of the device with incident energy of $1 \mathrm{~mJ} / \mathrm{cm}^{2}$. The average lifetime of electron can be estimated approximately by fitting a decay of the open-circuit voltage transient with

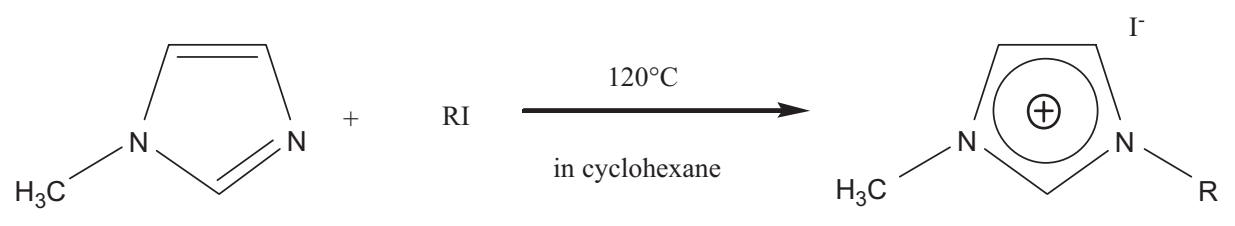

Scheme 1. 
$\exp \left(-t / \tau_{\mathrm{e}}\right)$, where $t$ is the time and $\tau_{\mathrm{e}}$ is an average time constant before recombination.

\section{Results and discussion}

Fig. 1 shows the photovoltaic characteristics of the DSSCs based on GPE and OLE containing IILs of different carbon chain lengths. From Fig. 1a, it is understandable that open-circuit voltages of the DSSCs $\left(V_{\text {OC }}\right)$ do not vary very much by incorporating IILs of different carbon chain lengths $(\mathrm{C} 3-\mathrm{C} 10)$. ( $V_{\mathrm{OC}}$ changes from 0.69 to $0.71 \mathrm{~V}$ for OLEs and 0.65 to $0.68 \mathrm{~V}$ for GPEs.) The shortcircuit densities $\left(J_{\mathrm{SC}}\right)$ of the DSSCs varied significantly for IILs containing carbon chain length from C3 to C10. For example, the $J_{\mathrm{SC}}$ value of the DSSCs based on OLE increases with increase in alkyl group of IIL from C3 to C8 and then decreases, whereas, a linear decrease in $J_{\mathrm{SC}}$ is observed for GPE-containing IIL with alkyl group from C3 to $\mathrm{C} 10$ (Fig. 1b). On the other hand, there was only little variation in fill factors (FF) of the DSSCs when the chain length of alkyl groups of IIL was varied for both OLE and GPE (Fig. 1c). In the similar manner, the efficiencies of the DSSCs based on GPE decrease from C3 to C10, whereas, a linear increase and decrease on the performances of the
DSSCs were noted for the IILs from C3-C7 to C8-C10, respectively, with OLE (Fig. 1d).

It is well known that the $V_{\mathrm{OC}}$ values of the DSSCs are related to the difference between the Fermi level for electrons in the $\mathrm{TiO}_{2}$ electrode and the redox potential of $\mathrm{I}^{-} / \mathrm{I}_{3}^{-}$. Actually, the increase of alkyl chain length would increase electron density in the $\mathrm{TiO}_{2}$ by suppressing charge recombination, causing the increase of Fermi level. Fig. 2a shows the photovoltage transients induced by pulse laser $(532 \mathrm{~nm})$ radiation for $\mathrm{TiO}_{2}$ electrodes in different pure IILs and Fig. 2b brings the correlation between electron lifetime $\left(\tau_{\mathrm{e}}\right)$ and viscosity of the pure IILs used in this study. Though there is an increase of electron recombination lifetime from $\mathrm{C} 3$ to $\mathrm{C} 10$, presence of 4-tertirary butyl pyridine (TBP) nullifies this effect. Because of this reason, there is not much difference in the $V_{\mathrm{OC}}$ of the DSSCs containing both OLE and GPE [18].

This characteristic variation in the $J_{\mathrm{SC}}$ (Fig. 1b) and conversion efficiency (Fig. 1d) of the DSSCs containing IIL may be correlated with different conductivities and viscosities of individual IIL. The relationship between the conductivity of both GPE and OLE with different IILs vs. the viscosity of pure IIL is shown in Fig. 3. It is well known that the IILs are highly viscous liquids and their viscosities increase with increase in chain length of alkyl group. This is a

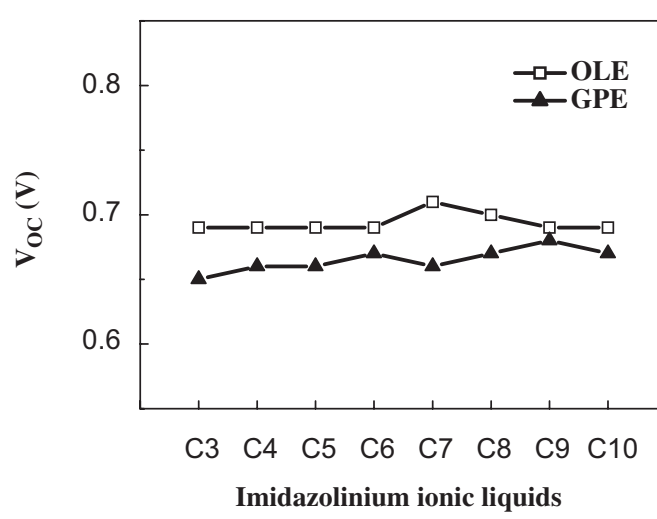

C

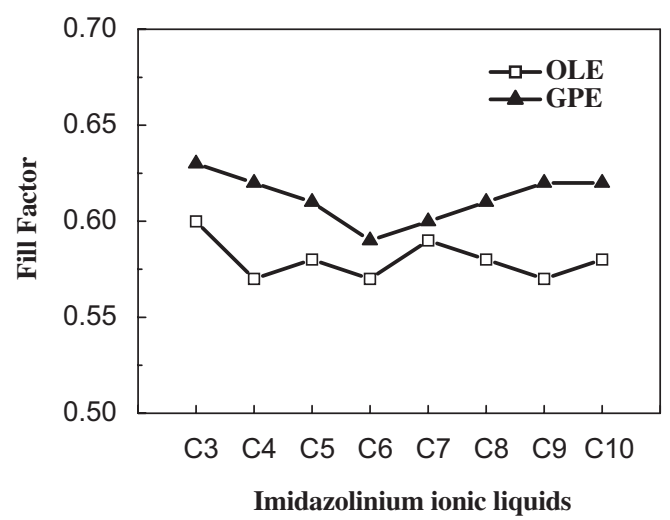

b

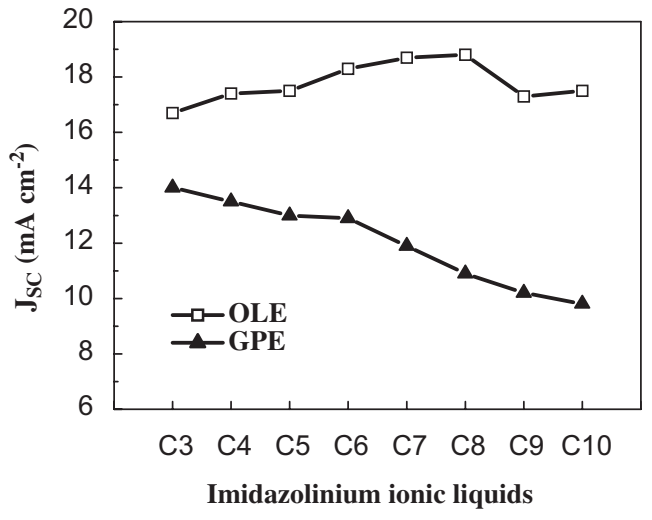

d

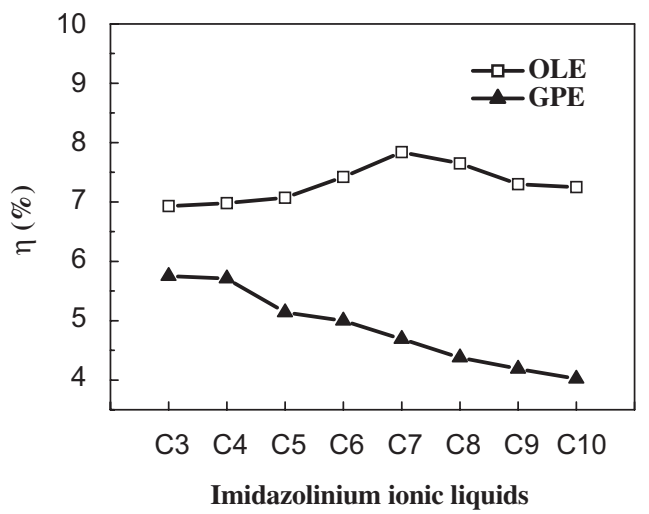

Fig. 1. Photovoltaic characteristics such as (a) $V_{\mathrm{OC}}$ (b) $J_{\mathrm{SC}}$ (c) FF, and (d) $\eta$ of the DSSCs containing OLE and GPE incorporated with IILs of different carbon chain lengths from $\mathrm{C} 3$ to $\mathrm{C} 10$. 
a

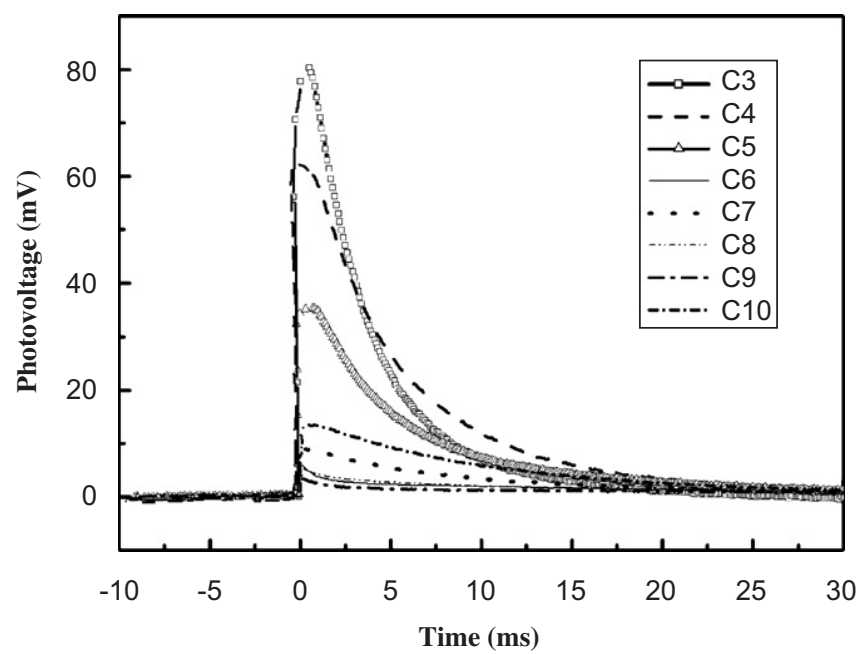

b

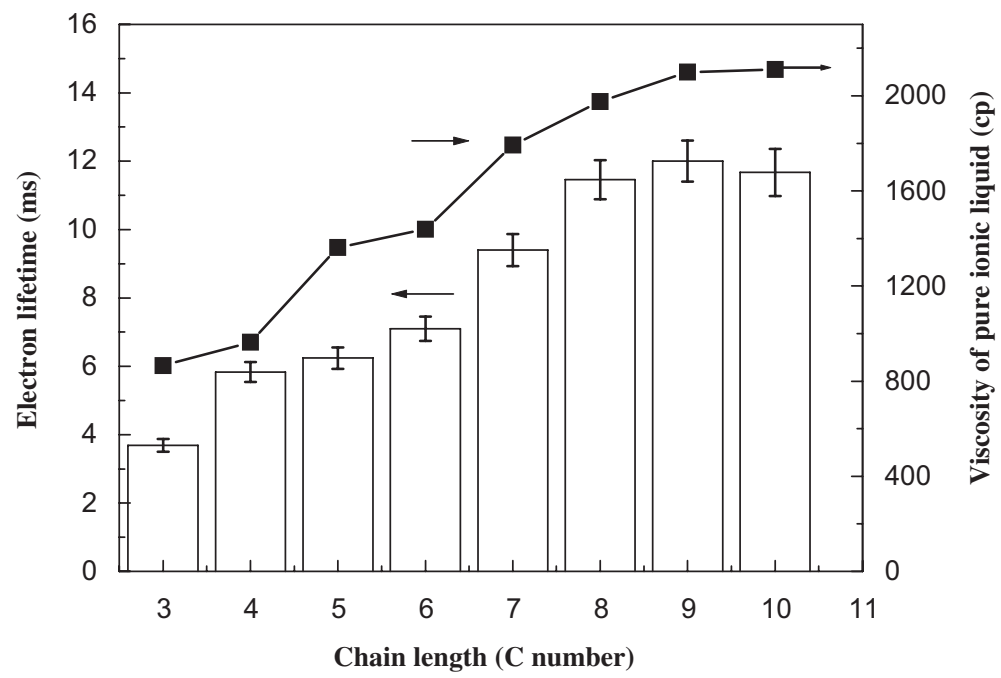

Fig. 2. (a) Photovoltage transients induced by pulse laser $(532 \mathrm{~nm})$ radiation for the $\mathrm{TiO}_{2}$ electrodes in the GPE with IILs containing different alkyl chain lengths (C3-C10). (b) Relationship between electron lifetimes in the $\mathrm{TiO}_{2}$ electrode and the viscosity of IILs under the same condition.

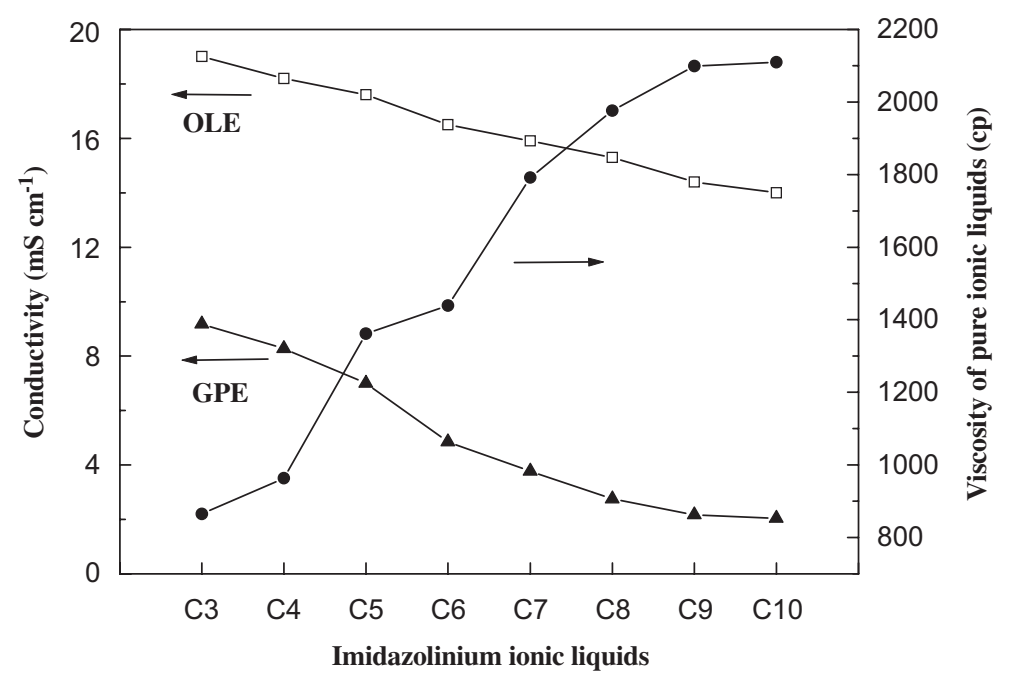

Fig. 3. Plots of conductivity of OLE and GPE vs. the viscosity of IILs containing different alkyl chain lengths (C3-C10). 
because of high van der Waals forces of attraction functioning between the molecules and this lowers diffusion of ions. Since the diffusion of ions in a liquid depends on its viscosity, the conductivity of the liquid decreases with increase in the viscosity. From Fig. 3, it is noted that IIL containing propyl group (C3) shows maximum conductivity in both the GPE and OLE and the conductivity decreases from $\mathrm{C} 3$ to $\mathrm{C} 10$. Naturally, higher conductivity values are obtained for OLE than the GPE irrespective of the different IILs.

From the previous literature, it has been observed that the diffusion coefficient of electrons injected in a $\mathrm{TiO}_{2}$ electrode $\left(D_{\mathrm{e}}\right)$ increases as a result of the multilayer adsorption of imidazolinium cations [21]. When the chain length of alkyl group in IIL increases, the carbon-carbon will have more chance to encounter, the van der Waals forces will increase in the presence of the longer chain length. The aggregation of these imidazolinium cations will be more and this leads to high $D_{\mathrm{e}}$ value. As a consequence of this, the $J_{\mathrm{SC}}$ value of the DSSC also increases. Though the conductivity decreases with increases in the chain length of IIL, both the effect of $\tau_{\mathrm{e}}$ and $D_{\mathrm{e}}$ overcome this. Consequently, the conversion efficiency of the DSSCscontaining OLE increases from $\mathrm{C} 3$ to $\mathrm{C} 7$. However, for GPE containing IILs from $\mathrm{C} 3$ to $\mathrm{C} 10$, a linear decrease in the performance of the DSSCs is observed. This may be correlated with the weak adsorption of imidazolinium cations on the $\mathrm{TiO}_{2}$ electrode as a result by trapping of ILL in polymer cages formed by the host matrix in GPE.

\section{Conclusions}

A comparative study on the photoelectrochemical characteristics of the DSSCs-containing PVDF-HFP as GPE and OLE both incorporated with different IILs containing different carbon chain lengths from $\mathrm{C} 3$ to $\mathrm{C} 10$ in MPN was carried out in this work. The conductivities $(\sigma)$ of both GPE and OLE decrease with increase in chain length of the alkyl group of IILs. The $V_{\mathrm{OC}}$ of the DSSCs remains almost stable with increase of alkyl chain length of ILLs for both the electrolytes and this is related with the dominating role of the TBP on the charge recombination behavior. The performance of the DSSCs based on OLE increases with the addition of IILs from $\mathrm{C} 3$ to $\mathrm{C} 7$, whereas, there is a linear decrease in the efficiency of the DSSCs incorporated with GPE electrolytes containing IILs of different carbon chain lengths from $\mathrm{C} 3$ to $\mathrm{C} 10$. This may be explained on the basis of increase in both electron lifetime and the diffusion coefficient of electron, and is in consistent with increase in viscosity of IILs.

\section{Acknowledgments}

This work was financially supported by the Academia Sinica, Taipei, Taiwan, the Republic of China, under Grant AS-94-TP-A02. This work was partially supported by the Taiwan Textile Research Institute (TTRI), Tucheng City, Taipei County, Taiwan. We also want to thank Professor King-Chuen Lin and his research group members, of Department of Chemistry, National Taiwan University, for the help in making the pulsed laser apparatus available to us.

\section{References}

[1] B. O'Reagen, M. Grätzel, Nature 353 (1991) 373.

[2] G. Wang, X. Zhou, M. Li, J. Zhang, J. Kang, Y. Lin, S. Fang, X. Xiao, Mater. Res. Bull. 39 (2004) 2113.

[3] O.A. Illeperuma, M.A.K.L. Dissanayake, S. Somasundaram, L.R.A.K. Bandara, Sol. Energy Mater. Sol. Cells 84 (2004) 117.

[4] J. Kang, W. Li, X. Wang, Y. Lin, X. Li, X. Xiao, S. Fang, J. Appl. Electrochem. 34 (2004) 301.

[5] Y.J. Kim, J.H. Kim, M.-S. Kang, M.J. Lee, J. Won, J.C. Lee, Y.S. Kang, Adv. Mater. 16 (2004) 1753.

[6] M. Masamitsu, M. Hiromitsu, M. Kikuo, K. Yoshimasa, T. Yoichi, Solid State Ionics 89 (1996) 263.

[7] Y. Liu, J.Y. Lee, L. Hong, J. Power Sources 129 (2004) 303.

[8] J.H. Kim, M.-S. Sung, Y.J. Kim, J. won, Y.S. Kang, Solid State Ionics 176 (2005) 579.

[9] P. Wang, S.M. Zakeeruddin, I. Exnar, M. Grätzel, Chem. Commun. (2002) 2972.

[10] S.R. Scully, M.T. Lloyd, R. Herrera, E.P. Giannelis, G.G. Malliaras, Synth. Met. 144 (2004) 291.

[11] T. Miyasaka, Y. Kijitori, T.N. Murakami, M. Kimura, S. Uegusa, Chem. Lett. (2002) 1250.

[12] P. Wang, S.M. Zakeeruddin, P. Comte, R. Charvet, R. HumphryBaker, M. Grätzel, J. Phys. Chem. B 107 (2003) 14336.

[13] K. Hara, T. Nishikawab, M. Kurashigea, H. Kawauchic, T. Kashimac, K. Sayamaa, K. Aikab, H. Arakawa, Sol. Energy Mater. Sol. Cells 85 (2005) 21.

[14] W. Kubo, K. Murakoshi, T. Kitamura, S. Yoshida, M. Haruki, K. Hanabusa, H. Shirai, Y. Wada, S. Yanagida, J. Phys. Chem. B 105 (2001) 12809

[15] S. Mikoshiba, S. Murai, H. Sumino, S. Hayase, Chem. Lett. (2002) 918.

[16] W. Kubo, S. Kambe, S. Nakade, T. Kitamura, K. Hanabusa, Y. Wada, S. Yanagida, J. Phys. Chem. B 107 (2003) 4374.

[17] H. Kusama, Y. Kinoshi, H. Sugihara, H. Arakawa, Sol. Energy Mater. Sol. Cells 80 (2003) 167.

[18] W. Kubo, T. Kitamura, K. Hanabusa, Y. Wada, S. Yanagida, Chem. Commun. (2002) 374.

[19] C.J. Barbe', F. Arendse, P. Comte, M. Jirousek, F. Lenzmann, V. Shklover, M. Grätzel, J. Am. Ceram. Soc. 80 (1997) 3157.

[20] K.-M. Lee, V. Suryanarayanan, K.-C. Ho, Sol. Energy Mater. Sol. Cells 90 (2006) 2398.

[21] P. Bonhote, A.-P. Dias, N. Papageorigiou, K. Kalyanasundaram, M. Grätzel, Inorg. Chem. 35 (1996) 1168. 